\title{
ЭКСПРЕСС МЕТОД КОЛИЧЕСТВЕННОГО ОПРЕДЕЛЕНИЯ СОДЕРЖАНИЯ АЛУНИТА В РУДЕ И ТЕХНОЛОГИЧЕСКИХ ПРОБАХ
}

\author{
Ч. М. Кашкай, Р. Б. Керимов, А. С. Амиров, Е. А. Кашкай \\ Институт Геологии и Геофизики \\ Национальной Академии Наук Азербайджана, г. Баку
}

Поступила в редакцию 29 января 2019 г.

\begin{abstract}
Аннотация: в статье предлагается альтернативная методика определения количественного содержания алунита в рудах и технологических пробах на основе рентгенофазового анализа. Сущность методики состочт в сопоставления величины наиболее интенсивного пика $20 \approx 30^{\circ}$ $(d=2,971)$ на рентгенограмме анализируемой пробы с таковыми для заранее приготовленных эталонных образиов. Преимущзеством метода при всей его быстроте и относительной дешевизне, является возможность определения количества алунита в пробе без специиальной пробоподготовки и использования химических реактивов.

Ключевые слова: алунит, руда, рентгенограмма, эталонные образиы, пробы, матрииа, Загликское месторождение.
\end{abstract}

\section{EXPRESS METHOD FOR QUANTITATIVE DETERMINATION OF THE CONTENT OF ALUNITE IN ORE AND TECHNOLOGICAL SAMPLES}

\begin{abstract}
: this article presents the results of an alternative method for determining the amount of alunite in ore and process samples based on X-ray phase analysis. The essence of the technique consists in comparing the magnitude of the most intense peak $2 \theta \approx 30^{\circ}(d=2,971)$ on the diffractometer of the analyzed sample with those for pre-prepared reference samples. A special advantage of this method, with all its speed and relative cheapness, is the ability to determine the amount of alunite in a sample without special sample preparation, the use of chemical reagents, and so on.
\end{abstract}

Keywords: alunite, ore, X-ray, reference samples, samples, matrix, Zaglik deposit.

\section{Введение}

Необходимость надежной диагностики минералов и определения количественного содержания фазового состава их агрегатов (в горных породах и рудах) возникает на разных стадиях поисковых и геологоразведочных работ, а также при решении задач технической и технологической минералогии. Особенно это актуально при технологических и экспериментальных исследованиях, а так же в случае промышленной эксплуатации алунитовых руд. Во всех этих случаях экспрессность анализа играет доминирующую роль.

В минералогическом отношении алунит по составу представляет собой основной сульфат алюминия и калия (или натрия) согласно формуле $(\mathrm{K}, \mathrm{Na}) \mathrm{Al}\left(\mathrm{SO}_{4}\right)_{3}(\mathrm{OH})_{6}$. Обычно, количественное содержание алунита в рудных пробах и технологических продуктах определяют химическими методами по содержанию сульфата, после чего производят пересчёт на количество алунитовой фазы. Это в том случае, если в руде нет других сульфатсодержащих минералов. При этом химический анализ является многочасовым и затратным процессом.

В некоторых случаях, содержание алунита рекомендуют определять термогравиметрическим методом по выделению $\mathrm{SO}_{3}$ в температурном интервале $750-850^{\circ} \mathrm{C}$, при условии отсутствия прочих минералов в руде с совпадающем эффектом уменьшения веса в этом же интервале. Однако при термогравиметрическом методе, даже в сочетании с дифференциально термической кривой, не всегда удается точно отсечь начало выделения серного ангидрида после выделения воды из алунита и каолинита (диккита) или других минералов, что снижает точность анализа [1]. При этом для термогравиметрического анализа требуется почти час времени.

Для удобства определения количества алунита в рудах по этим методикам был предложен теоретически рассчитанный график зависимости аналитических данных $\mathrm{SO}_{3}$, с учетом пропорции калия и натрия в составе алунита [1]. 
Однако наиболее быстрым и надежным можно считать количественный рентгенофазовый анализ, методическая процедура которого широко освящена в литературе [2]. Основным преимуществом этого метода является высокая чувствительность и избирательность по отношению к отдельным минералам и значительное сокращение времени анализа (практически до 10 минут).

Целью работы было освоение новой экспресс методики по определению количественного содержания алунита в руде и технологических пробах на основе рентгенофазового анализа.

\section{Методика подготовки материала и проведение количественного рентгенофазового анализа}

Сущность методики состоит в сопоставлении величины наиболее интенсивного пика на рентгенограмме анализируемой пробы с таковыми для заранее приготовленных эталонных образцов. Самым интенсивным пиком алунита считается $\mathrm{d}=2,971$, который, как показали многочисленные измерения, почти линейно меняется в зависимости от содержания алунита в минеральной смеси. Исследования проводились на приборе RIGAKU «MiniFlex 600».

Для сопоставления были приготовлены 18 эталонных образцов, содержащих алунит от 5\% до 90\% с шагом 5\% (в весовом выражении). В качестве нейтральной матрицы использовался кек, полученный после полного выщелачивания алунита щелочным раствором (при $\mathrm{t}=90^{\circ} \mathrm{C}$ в течение 6 часов) из алунитовой руды Загликского месторождения Азербайджана. Отсутствие алунита в кеке определялось методом рентгенофазового анализа по отсутствию диагностического пика (лимит обнаружения алунита в исследу- емой минеральной смеси соответствовал $1-1,5 \%$, что вполне достаточно для решения вышеуказанных целевых задач.). Остаточными минералами в кеке были кварц, диккит (каолинит) и гематит, т.е. те же основные минералы, что и в исходной руде. Тщательно отобранный чистый алунит (90\%) из того же месторождения был измельчен и смешан с кеком в нижеуказанных пропорциях, с учетом 90\% чистоты (табл. 1).

Для исследования отобран пик с интенсивной отражений $2 \theta \approx 30^{\circ}$ ( $\mathrm{d}=2,971$ ) (табл. 2)

Эталонные образиьы

\begin{tabular}{|c|c|c|c|c|}
\hline $\begin{array}{c}\text { № } \\
\text { пр. }\end{array}$ & $\begin{array}{c}\text { Матрица } \\
(\text { кек) (г) }\end{array}$ & $\begin{array}{c}\text { Алунит } \\
(90 \%) \\
(г)\end{array}$ & $\begin{array}{c}\text { Эталонные } \\
\text { образцы (в } \\
\text { весовых \%) }\end{array}$ & $\begin{array}{c}\text { Навеска } \\
\text { эталонных } \\
\text { образцов (г) }\end{array}$ \\
\hline 1 & 1,89 & 0,11 & 5 & 2 \\
\hline 2 & 1,78 & 0,22 & 10 & 2 \\
\hline 3 & 1,67 & 0,33 & 15 & 2 \\
\hline 4 & 1,56 & 0,44 & 20 & 2 \\
\hline 5 & 1,45 & 0,55 & 25 & 2 \\
\hline 6 & 1,34 & 0,66 & 30 & 2 \\
\hline 7 & 1,23 & 0,77 & 35 & 2 \\
\hline 8 & 1,12 & 0,88 & 40 & 2 \\
\hline 9 & 1,01 & 0,99 & 45 & 2 \\
\hline 10 & 0,90 & 1,1 & 50 & 2 \\
\hline 11 & 0,79 & 1,21 & 55 & 2 \\
\hline 12 & 0,68 & 1,32 & 60 & 2 \\
\hline 13 & 0,57 & 1,43 & 65 & 2 \\
\hline 14 & 0,46 & 1,54 & 70 & 2 \\
\hline 15 & 0,35 & 1,65 & 75 & 2 \\
\hline 16 & 0,24 & 1,76 & 80 & 2 \\
\hline 17 & 0,13 & 1,87 & 85 & 2 \\
\hline 18 & 0,02 & 1,98 & 90 & 2 \\
\hline
\end{tabular}

Таблица 2

Пики эталонных образиов с интенсивностями отражений $2 \theta \approx 30^{\circ}(d=2,971)$

\begin{tabular}{|c|c|c|c|c|c|}
\hline & $\begin{array}{c}\text { Эталонные } \\
\text { образцы (в \%) }\end{array}$ & Raw & Smooth & $\begin{array}{c}\text { Smooth (without } \\
\text { background) }\end{array}$ & $\begin{array}{c}\text { После внесения } \\
\text { поправок на ли- } \\
\text { нейность (рис. 1) }\end{array}$ \\
\hline 1 & 5 & 2937 & 2781 & 1466 & 1466 \\
\hline 2 & 10 & 4324 & 4007 & 2792 & 2892 \\
\hline 3 & 15 & 6047 & 5729 & 4573 & 4400 \\
\hline 4 & 20 & 7559 & 7529 & 6392 & 6092 \\
\hline 5 & 25 & 8916 & 8754 & 7719 & 7719 \\
\hline 6 & 30 & 10301 & 10171 & 9159 & 9159 \\
\hline 7 & 35 & 12054 & 12070 & 11092 & 10592 \\
\hline 8 & 40 & 13396 & 13669 & 12759 & 12359 \\
\hline 9 & 45 & 14329 & 14502 & 13555 & 13755 \\
\hline 10 & 50 & 15731 & 15374 & 14502 & 17066 \\
\hline 11 & 55 & 17667 & 17724 & 16966 & 18547 \\
\hline 12 & 60 & 19793 & 19581 & 18747 & 20132 \\
\hline 13 & 65 & 20280 & 20452 & 19732 & 21665 \\
\hline 14 & 70 & 23227 & 22309 & 21665 & 23349 \\
\hline 15 & 75 & 25000 & 24394 & 23749 & 26446 \\
\hline 16 & 80 & 26332 & 25644 & 25076 & 28052 \\
\hline 17 & 85 & 27202 & 27009 & 26440 & 28752 \\
\hline 18 & 90 & 28510 & 29244 & & \\
\hline
\end{tabular}




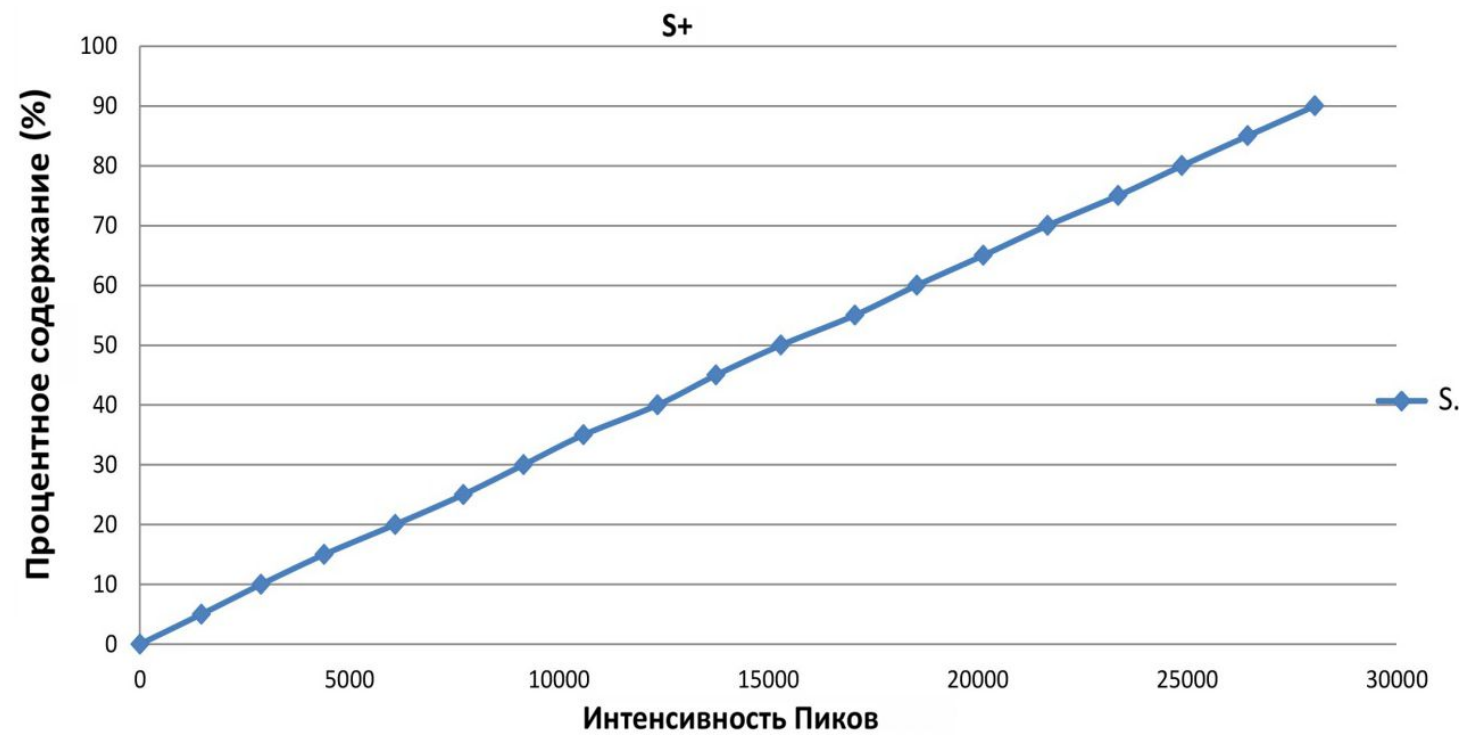

Puc. 1. График максимальных значений пиков стандартов (сглаженная линия).

\section{Обсуждение результатов}

При нанесении на график максимальных значений пиков для каждого эталонного образца (за вычетом фонового значения рентгенограммы) в координатах «Интенсивность пиков - Процентное содержание» была получена практически прямая линия с небольшими отклонениями (последние, скорее всего, связаны с суммарными ошибками процедуры, Допустимая ошибка прибора при проведении фазового анализа составляет при $2 \theta \approx 30^{\circ} \pm 0,06$ (рис. 1 ).

Вопрос о влиянии соотношения калия и натрия в составе алунита на аналитическую точность, как оказалось, не столь существенна по ряду причин. В составе алунитов Загликского месторождения процентное соотношения калия-натрия приблизительно соответствует 70-30\%. В целом по месторождению это соотношение монотонно сохраняется. И поэтому как в эталонах, так и в анализируемых пробах используются сопоставимые параметры. Кроме того, согласно рентгенографическим параметрам, если для чистого калиевого алунита главная линия приходится на 2,98, то для чистого натриевого алунита эта линия соответствует значению 2,96. Эта разница $(0,02)$ на используемом приборе практически не улавливается.

Количественное содержание алунита в руде можно определить как по графику (рис. 1), так и по эм

Институт Геологии и Геофизики Национальной Академии Наук Азербайджана, Баку

Кашкай Чингиз Мирали руководитель отдела, доктор геолого-минералогических наук

E-mail:chkashkay@bk.ru; Тел.:+9(9412)5105618

Керимов Рауф Балахмед, вед. научной сотрудник отдела, кандидат геолого-минералогических наук

E-mail:anrugo@rambler.ru; Тел.: +9 (9412) 5105618

Амиров Азер Сабир, вед. научной сотрудник, аналитик, кандидат геолого-минералогических наук

Кашкай Егана Аликулы, научный сотрудник пирической формуле (1), полученной при обработке многочисленных данных рентгенографических исследований.

$$
\mathrm{C}=\frac{40 \times \mathrm{X}-1565}{12413}
$$

где: $\mathrm{C}$ - весовой процент алунита в пробе; $\mathrm{X}$ - интенсивность пика алунита в пробе по данным рентгенофазового анализа.

По этой формуле допустимая ошибка составляет \pm $0,6-1 \%$.

Как видно из представленных примеров, использование указанного способа позволяет повысить достоверность оценки количественного содержания алунита в алунитовых рудах, а так же в продуктах технологических процессов.

Особым преимуществом этого метода при всей его быстроте и относительной дешевизне, является возможность определения количества алунита в пробе без специальной пробоподготовки и использования химических реактивов.

\section{ЛИТЕРАТУРА}

1. Кашкай, М. А. Алуниты, их генезис и использование. Том I. / М. А. Кашкай. - Изд. «Недра». Москва, 1970. - 396 с.

2. Сведения о методиках (методах) измерений. Дифрактометр рентгеновский «MiniFlex 600». Руководство по эксплуатации. 2015

Institute of Geology and Geophysics of National Academy of Sciences of Azerbaijan, Baku

Kashkai Ch. M., Chief of Department, doctor of geological and mineralogical sciences

E-mail: chkashkay@bk.ru; Tel: +9(9412)5105618

Kerimov R. B., liding researcher associate, candidate of geological and mineralogical sciences

E-mail:anrugo@rambler.ru; Tel: +9 (9412) 5105618

Amirov A. S., liding researcherer, analyst, candidate of geological and mineralogical sciences

Kashkai Y. A., researcher associate 